\title{
Nurses' Knowledge and Practices Regarding Neonates with Tracheoesophageal Fistula at Assuit University Children Hospital
}

\author{
Amany G. Abd-Elhamed, Mohamed A. Osman \& Fathia Z. Mohammed \\ Clinical Demonstrator in Pediatric Nursing Department, Faculty of Nursing, Assuit University Egypt. \\ Professor of Pediatric Surgery, Faculty of Medicine, Assuit University Egypt. \\ Assistant Professor of Pediatric Nursing, Faculty of Nursing, Assuit University Egypt.
}

\begin{abstract}
Tracheoesophageal Fistula (TEF) is one of the most serious congenital anomalies in neonates with a high rate of morbidity and mortality that require a very special care pre \& post operatively. The Aim of this study was to assess nurses' knowledge and practices regarding care of neonates with tracheoesophageal fistula in neonatal intensive care unit at Assuit University Children Hospital. A descriptive research Design was used to conduct this study. The subjects included a convenient Sample of 40 nurses caring for neonates with TEF who admitted to NICU at Assuit university children hospital. Two Tools were used to collect the necessary data, structured interview questionnaire and observation checklist which were developed by the researcher. Results of this study revealed that $(62.5 \%)$ of the studied nurses had unsatisfactory level of knowledge regarding care of neonates with TEF while $(67.5 \%)$ of them had competent level of practices regarding neonates with TEF. There were statistically significant differences between total mean scores of the studied nurses' level of knowledge and practices $\mathrm{p}=0.045$. The study Concluded that nurses had unsatisfactory level of knowledge and competent level of practices regarding neonates with TEF. It was Recommended that implementation of periodical educational programs for nurses working at NICU are mandatory.
\end{abstract}

Key words: Tracheoesophageal Fistula (TEF), Congenital Anomalies, NICU \& Nurses.

\section{Introduction}

Tracheoesophageal fistula (TEF) is an abnormal connection between the esophagus and the trachea. It is a congenital or acquired communication between the trachea and esophagus which often lead to severe and fatal pulmonary complications (Rebort, et al., 2009).

TEF may result in gastric reflux after feeding, allowing gastric acids to cross the fistula, thus irritating the trachea (Farlex, 2012).

The manifestations of TEF are failure to pass suction catheter, or nasogastric tube at birth, excessive oral secretions, vomiting and unexplained cyanosis after initial feeding. The presence of a fistula between the esophagus and trachea causes oral intake to enter the lungs or large amount of air to enter the stomach. Coughing, chocking and severe abdominal distension can occur. Eventually, aspiration pneumonia and severe respiratory distress will develop in the untreated child and death may occur without surgical intervention. Neonates may be with other serious anomalies, such as congenital heart disease, imperforated anus, intestinal obstruction and anal atresia. The incidence of these associations is around $20 \%$ in esophageal atresia population, but two or more anomalies occur in nearly half of neonates (James, et al., 2007).

Fetal magnetic resonance imaging (MRI) has gained more attention for prenatal diagnosis of congenital anomalies, although the diagnosis is established on the basis of clinical signs and symptoms (Hockenberry, et al., 2011). The exact type and location of the fistula can be determined using radiopaque catheter which allows pictures to be taken of the esophagus. X-ray may show air in the bowels. Surgical repair of TEF is associated with complications including stricture due to gastric acid erosion of the shortened esophagus, leak of contents at the point of anastomosis, recurrence of fistula, increased gastro esophageal reflux (Rebort, et al., 2009).

Nursing responsibility for detection of this serious malformation begins immediately after birth. For the infant who presents with the classic signs and symptoms of esophageal atresia (EA) the major concern is the establishment of a patent airway and prevention of further respiratory compromise. Cyanosis is usually a result of laryngeal spasm caused by over flow of saliva into the larynx from the proximal esophageal pouch or aspiration and normally resolves after removal of the secretions from the oropharynx by suctioning. The pre and post-operative management of the infant is as per general care of the surgical infant. However there are some nursing considerations pertinent to care of the infant with EA/TEF (Hockenberry, et al., 2011).

Neonatal care pre- operatively includes stabilization of the infant's respiratory status with avoidance of 
endotracheal intubation, suction tube drainage of the blind, proximal esophageal pouch, semi-prone positioning of the child to minimize the risk of gastroesophageal reflux and aspiration via the occult fistula of the distal trachea. Monitoring of vital signs and vascular access should also be performed as precautionary measures (Grosfeld \& Ladd, 2005).

Post- operative care of these neonates is the same as for any high- risk newborn. Adequate thermoregulation is provided, double- lumen nasogastric catheter is attached to low-suction and the gastrostomy tube is returned to gravity drainage until feedings are tolerated. If a thoracotomy is performed and a chest tube is inserted, attention to the appropriate function of the closed drainage system is imperative. Pain management in the post-operative period is important (Rodgers et al, 2015).

\section{Significance of the study}

It comes as no surprise to anyone involved in the care of neonates that TEF is one of the most serious surgical emergencies in neonates, which require not only immediate diagnosis and correction but also a continuous skilled nursing care of the neonates pre \& postoperatively, appropriate and update knowledge to decrease the rate of morbidity, mortality, the hospital stay and cost. So this study conducted to assess nurses' knowledge and practices regarding care of neonates with TEF in neonatal intensive care unit at Assuit university children hospital.

\section{Aim of the study}

The aim of this study was to assess nurses' knowledge and practices regarding neonates with tracheoesophageal fistula in neonatal intensive care unit at Assuit university children hospital.

\section{Subjects \& method}

\section{Research Design}

A descriptive research design was used to conduct this study.

\section{Setting}

This study was conducted in the neonatal intensive care unit at Assuit University Children Hospital.

\section{Subjects}

A convenient sample of 40 nurses caring for neonates with TEF who admitted to NICU at Assuit University Children Hospital were included in the study.

\section{Tools of data collection}

Two tools were used to collect the necessary data:

Tool (I): Structured Questionnaire sheet

Which was developed by the researcher after reviewing related literatures to assess nurses knowledge about neonates with TEF and it included two parts:-

\section{Part (1)}

Personal characteristics of the studied nurses such as age, sex, marital status, educational level, years of experience and attending related training program.

Part (2)

Questions to assess nurses' knowledge regarding to TEF. It included (11) questions about TEF such as, definition, signs and symptoms, neonates risk for developing TEF, diagnosis, complications, management, Pre\& Post- operative nursing care of neonates with TEF, gastrostomy tube feeding for neonates with TEF post operatively, nasogastric tube feeding for neonates with TEF post operatively, also the nurses knowledge about oral feeding for neonates with TEF post operatively.

\section{Tool (II): Observation checklist Sheet}

The observation checklist sheets which was developed by the researcher based on related pediatric and critical nursing procedures manual (Elizabeth et al., 2006) to assess Nurses' Practices regarding neonates with TEF and it included the following procedures: hand washing (12 steps), vital signs (axillary temperature (13 steps), pulse (10 steps), respiration (9 steps), suctioning \{ naso and oro pharyngeal (21 steps), endotracheal tube (25 steps) $\}$, positioning (7 steps), oxygen therapy (10 steps), intravenous infusion \{cannula connection (14 steps), I.V infusion (13 steps), follow up chart for I.V line (7 steps) \}, mouth care ( 6 steps), care of the chest tube (12 steps), feeding (gastrostomy feeding (18 steps), nasogastric tube feeding (22 steps), oral feeding \{ giving oral rehydration solution ( 8 steps), bottle feeding (13 steps) \} and gastrostomy care (12 steps).

\section{Scoring system for knowledge}

- A score of two grades was given for correct answer, one for incorrect answer and zero for don't know. There was 11 questions total score for them 22 .

- For each part, the scores of the items were summed up and the total divided by number of the items giving a mean score for the part. These scores were converted in to a percent, mean and S.D were computed.

- The nurses' knowledge was considered satisfactory if the percent score is $65 \%$ or more and unsatisfactory if scored less than $65 \%$.

- Scoring system for practices

- A score of two grades was given for procedure done competent, one for done incompetent and zero for not done. There was 174 observation items total score for them 348 .

- For each part, the scores of the items were summed up and the total divided by number of the items giving a mean score for the part. These scores were 
converted in to a percent, mean and S.D were computed.

- The nurses' practices was considered competent if the percent score is $70 \%$ or more and incompetent if scored less than $70 \%$.

\section{Method}

- An official permission was obtained from the director of NICU at Assuit university children hospital to collect the necessary data for this study.

- The validity and reliability were done for Tool I \& Tool II by a jury of 5 experts from both pediatric nursing and pediatric surgery fields.

- Internal consistency was measured by alpha Cronbach's test for tool $\mathrm{I}$ and it's result was $\mathrm{R}=$ $0.07 \%$ and equivalence was measured for tool II by using interpreter (inter observer technique) $\mathrm{R}=75 \%$

\section{A pilot study}

A pilot study was carried out on $10 \%$ of nurses (4 nurses) to test the clarity and applicability of the study tools and to estimate time needed to fulfill each sheet and they included in the study sample.

\section{Field of the work}

This study was carried out through a period of three months from (the beginning of April 2015 to the end June 2015). It was done every other day at NICU. Interviewing of studied nurses was conducted according to their available time in morning shift to collect data; two or three nurses were interviewed per day. The time needed for each interview questionnaire sheet ranged from 20-25 minutes according to the response of the participant nurses. Indirect observation for nursing practices regarding neonates with TEF was done individually for each nurse. The time needed for observing each nurse ranged from 3-4 hours. Only one nurse observed per day.

\section{Ethical considerations}

- Research proposal was approved from Ethical Committee in the Faculty of Nursing.

- There was no risk for study subject during application of the research.

- Written consent was obtained from nurses to participate in the study, the nature and purpose of the study was explained by the researcher and they were assured that the data of this research will used only for the research purpose.

- Confidentiality and anonymity were assured.

Statistical analysis

Data entry and data analysis were done by using SPSS program (Statistical Package for Social Science) version 16. Data were presented as number, percentage, mean and standard deviation. Chi- square test and fisher exact test were used to compare quantitative data. Pearson correlation was used to measure correlation between score of knowledge and practices. $\mathrm{P}$ value considered statistically significant when $\mathrm{p}<0.05$.

\section{Results}

Table (1): Distribution of the studied nurses according to their personal characteristics.

\begin{tabular}{|c|c|c|}
\hline Items & No. $(n=40)$ & $\%$ \\
\hline \multicolumn{3}{|l|}{ Sex } \\
\hline Female & 40 & 100.0 \\
\hline \multicolumn{3}{|l|}{ Marital status } \\
\hline Single & 9 & 22.5 \\
\hline Married & 30 & 75.0 \\
\hline Divorced & 1 & 2.5 \\
\hline \multicolumn{3}{|l|}{ Age } \\
\hline Less than 20 years & 1 & 2.5 \\
\hline From 20 to less than 30 years & 31 & 77.5 \\
\hline From 30 to less than 40 years & 8 & 20.0 \\
\hline \multicolumn{3}{|l|}{ Educational level } \\
\hline Health Technical Institute & 6 & 15.0 \\
\hline Technical Institute of Nursing & 10 & 25.0 \\
\hline Secondary School of Nursing & 24 & 60.0 \\
\hline \multicolumn{3}{|l|}{ Years of experience } \\
\hline Less than 5 years & 10 & 25.0 \\
\hline From 5 to less than 10 years & 17 & 42.5 \\
\hline From 10 to less than 15 years & 8 & 20.0 \\
\hline 15 year or more & 5 & 12.5 \\
\hline
\end{tabular}




\section{Nurses didn't attend training program about caring of neonates with TEF}

40

100.0

Table (2): Distribution of the studied nurses' knowledge regarding tracheoesophageal fistula in neonates: $\mathbf{N}=40$.

\begin{tabular}{|c|c|c|c|c|c|c|}
\hline \multirow{2}{*}{ Items } & \multicolumn{2}{|c|}{ Correct } & \multicolumn{2}{|c|}{ Incorrect } & \multicolumn{2}{|c|}{ Don't know } \\
\hline & No. & $\%$ & No. & $\%$ & No. & $\%$ \\
\hline Definition of TEF & 25 & 62.5 & 9 & 22.5 & 6 & 15.0 \\
\hline Signs and symptoms of TEF & 28 & 70.0 & 5 & 12.5 & 7 & 17.5 \\
\hline Neonates risk for developing TEF & 10 & 25.0 & 19 & 47.5 & 11 & 27.5 \\
\hline Diagnosis of TEF & 21 & 52.5 & 15 & 37.5 & 4 & 10.0 \\
\hline Complications of TEF & 24 & 60.0 & 8 & 20.0 & 8 & 20.0 \\
\hline Management of TEF & 23 & 57.5 & 12 & 30.0 & 5 & 12.5 \\
\hline Pre-operative nursing care of neonates with TEF & 33 & 82.5 & 4 & 10.0 & 3 & 7.5 \\
\hline Post-operative nursing care of neonates with TEF & 30 & 75.0 & 5 & 12.5 & 5 & 12.5 \\
\hline $\begin{array}{l}\text { Knowledge about gastrostomy tube feeding in } \\
\text { neonates with TEF post operatively }\end{array}$ & 21 & 52.5 & 9 & 22.5 & 10 & 25.0 \\
\hline $\begin{array}{l}\text { Knowledge about nasogastric feeding in neonates } \\
\text { with TEF post operatively }\end{array}$ & 14 & 35.0 & 18 & 45.0 & 8 & 20.0 \\
\hline $\begin{array}{l}\text { Knowledge about oral feeding in neonates with } \\
\text { TEF post operatively }\end{array}$ & 26 & 65.0 & 6 & 15.0 & 8 & 20.0 \\
\hline Mean \pm SD & & & & .17 & & \\
\hline
\end{tabular}

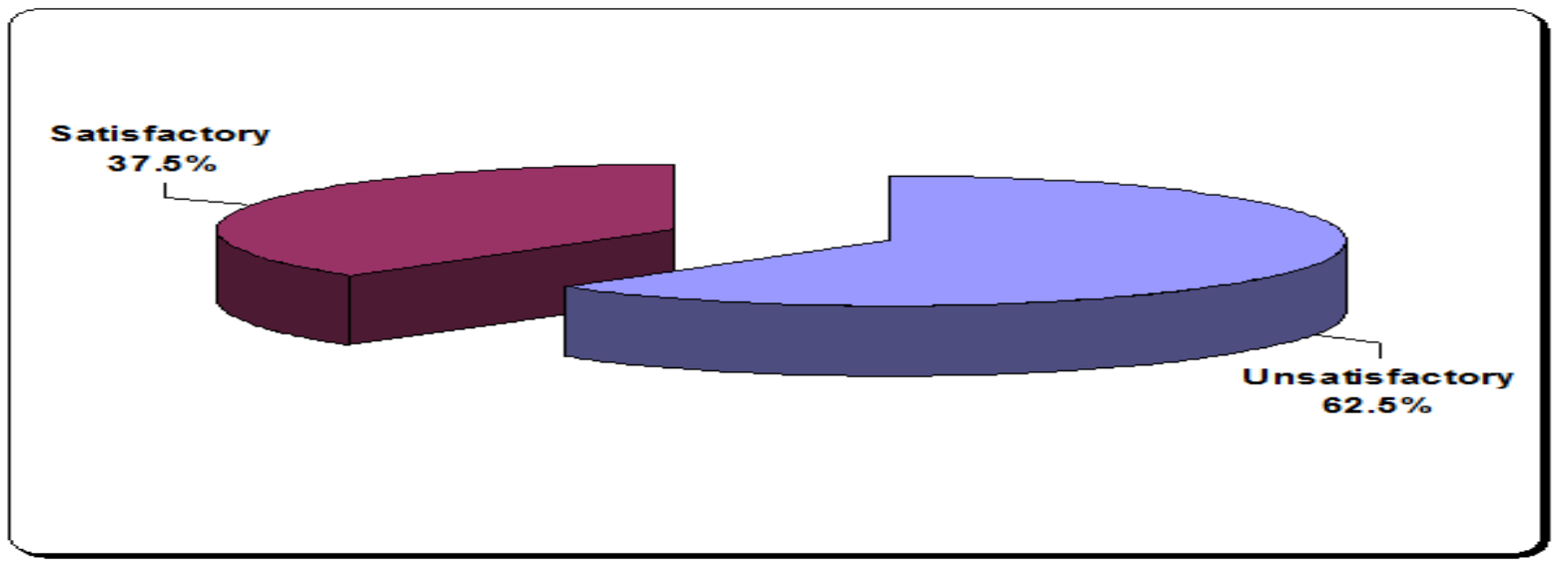

Figure (1): Total level of the studied nurses' knowledge regarding tracheoesophageal fistula

Table (3): Total levels of the studied nurses' practices regarding care of neonates with tracheoesophageal fistula in each procedure.

\begin{tabular}{|l|c|c|c|c|}
\hline \multirow{2}{*}{} & \multicolumn{2}{c|}{ Incompetent } & \multicolumn{2}{c|}{ Competent } \\
\cline { 2 - 5 } & No. & $\%$ & \multicolumn{2}{c|}{ No. } \\
\hline \hline Hand washing & 17 & 42.5 & 23 & 57.5 \\
\hline Vital signs: taking axillary temperature & 23 & 57.5 & 17 & 42.5 \\
\hline Suctioning & 6 & 15.0 & 34 & 85.0 \\
\hline Naso and oro pharyngeal suctioning & 0 & 0.0 & 40 & 100.0 \\
\hline b-Endotracheal tube suctioning & 33 & 82.5 & \multicolumn{3}{|c|}{7} & 17.5 \\
\hline Mouth care & 8 & 20.0 & 32 & 80.0 \\
\hline Positioning (Semi-setting position) & 4 & 10.0 & 36 & 90.0 \\
\hline Oxygen therapy & & & \multicolumn{3}{|c|}{} \\
\hline Intravenous infusion & 1 & 2.5 & 39 & 97.5 \\
\hline a-Cannula connection
\end{tabular}




\begin{tabular}{|c|c|c|c|c|}
\hline & \multicolumn{2}{|c|}{ Incompetent } & \multicolumn{2}{|c|}{ Competent } \\
\hline & No. & $\%$ & No. & $\%$ \\
\hline b-I.V infusion steps & 1 & 2.5 & 39 & 97.5 \\
\hline c-Follow up chart for I.V line & 0 & 0.0 & 40 & 100.0 \\
\hline Care of the chest tube & 30 & 75.0 & 10 & 25.0 \\
\hline Feeding (Gastrostomy feeding) & 15 & 37.5 & 25 & 62.5 \\
\hline Gastrostomy care & 4 & 10.0 & 36 & 90.0 \\
\hline Mean \pm SD & & & & \\
\hline
\end{tabular}

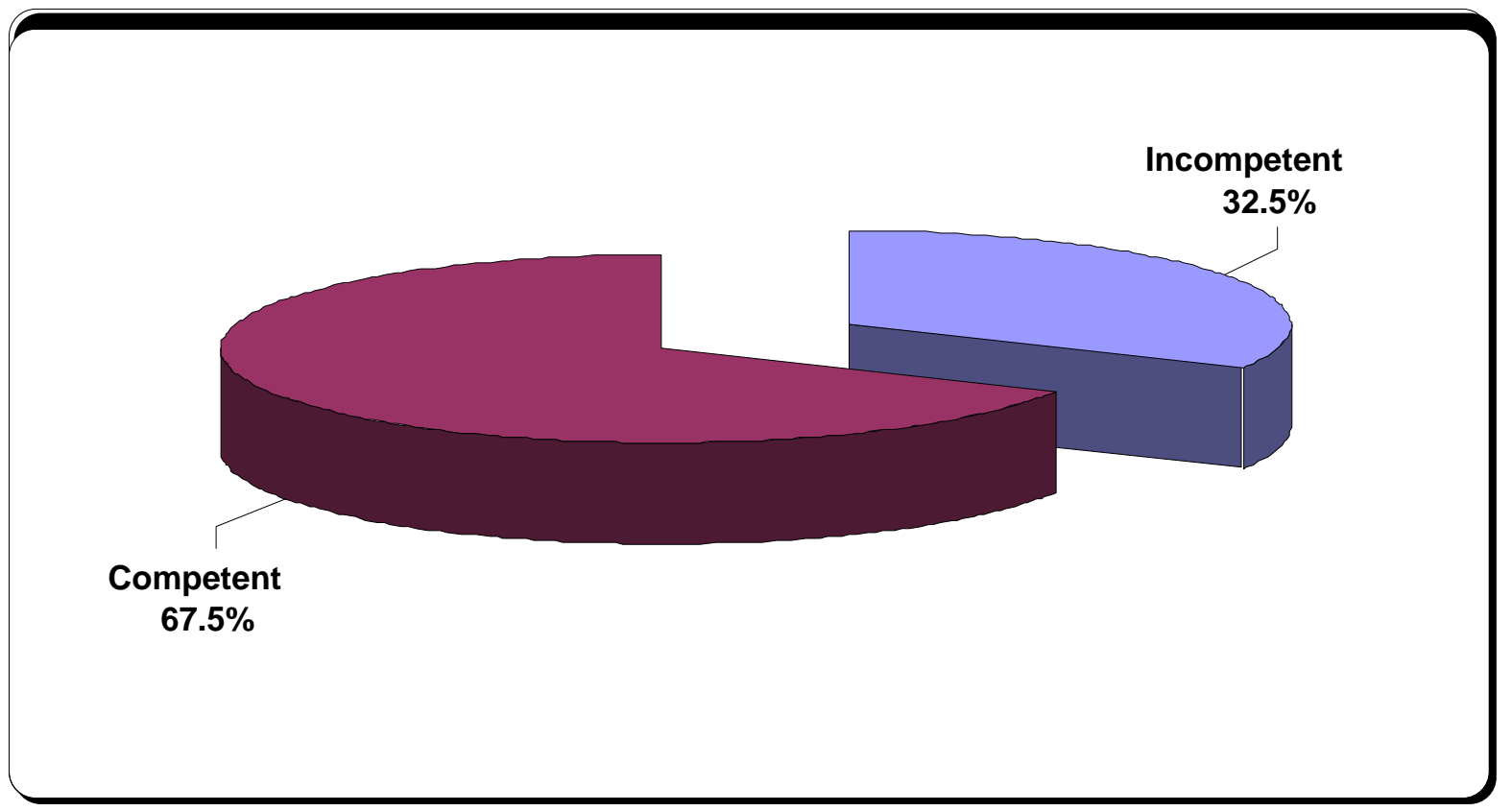

Figure (2): Total level of the studied nurses' practices regarding neonates with tracheoesophageal fistula.

Table (4): Relation between total scores of the studied nurses' level of knowledge and practices.

\begin{tabular}{|c|c|c|c|c|c|c|}
\hline \multirow{3}{*}{\multicolumn{2}{|c|}{ Items }} & \multicolumn{4}{|c|}{ Level of Knowledge } & \multirow{3}{*}{$\begin{array}{c}\mathbf{X}^{\mathbf{2}} \\
\text { (P-value) }\end{array}$} \\
\hline & & \multicolumn{2}{|c|}{ Unsatisfactory } & \multicolumn{2}{|c|}{ Satisfactory } & \\
\hline & & No. & $\%$ & No. & $\%$ & \\
\hline \multirow{2}{*}{ level of Practices } & incompetent & 11 & 44.0 & 2 & 13.3 & \multirow{2}{*}{$\begin{array}{c}4.02 \\
\left(0.045^{*}\right)\end{array}$} \\
\hline & competent & 14 & 56.0 & 13 & 86.7 & \\
\hline
\end{tabular}

Table (5): Correlation between total knowledge score and total practices score.

\begin{tabular}{|l|c|c|}
\hline \multirow{2}{*}{} & \multicolumn{2}{|c|}{ Level of Knowledge } \\
\cline { 2 - 3 } & r-value & P- value \\
\hline Level of Practices & 0.436 & $0.005^{* *}$ \\
\hline
\end{tabular}

Table (1): Shows distribution of the studied nurses according to their personal characteristics. It was found that all the studied nurses $(100 \%)$ were female, three quarters $(75 \%)$ of them were married and more than three quarters $(77.5 \%)$ of them were in the age group ranged from 20 to less than 30 . As regard their educational level, it was found that $60 \%$ of nurses were graduated from secondary school of nursing. According to years of experience, it was noticed that $42.5 \%$ of them had experience from 5 to less than 10 years while only $12.5 \%$ of them had experience of 15 year or more. Also, all studied 
nurses $(100 \%)$ did not attend training program about caring of neonates with TEF.

Table (2): Illustrates the distribution of the studied nurses' knowledge regarding TEF in neonates. It was found that $62.5 \%$ of the studied nurses define TEF correctly, more than two thirds of them (70\%) correctly respond the signs and symptoms of TEF, less than half $(47.5 \%)$ of them had incorrect answer regarding neonates risk for developing TEF. According to diagnosis of TEF more than half $(52.5 \%)$ of them had correct answer. As regard the complications and management of TEF $(60 \%$ \& $57.5 \%$ ) of them had correct answer respectively. Almost $(82.5 \%)$ of them had correct answer about pre-operative nursing care of neonates with TEF, three quarter $(75 \%)$ of them had correct answer about post-operative nursing care of neonates with TEF and more than half $(52.5 \% \& 35 \%)$ of them respond correctly about gastrostomy tube and nasogastric tube feeding in neonates with TEF post operatively respectively. According to the nurses' knowledge about oral feeding in neonates with TEF post operatively $65 \%$ of them had correct answer.

Figure (1): Presents the total level of the studied nurses' knowledge regarding TEF in neonates, it was found that more than one third $(37.5 \%)$ of nurses had satisfactory level of knowledge while less than two thirds $(62.5 \%)$ of them had unsatisfactory level of knowledge

Table (3): Presents the total level of the studied nurses' practices regarding care of neonates with tracheoesophageal fistula. It was found that $57.5 \%$ of the studied nurses had competent level of practices related to hand washing and incompetent level of practices related to taking axillary temperature, the majority $(97.5 \%, 90 \%, 85 \%)$ of them had competent level of practices related to naso and oro pharyngeal suctioning, semi-setting position, oxygen therapy, cannula connection, I.V infusion steps and gastrostomy care respectively and all of them $(100 \%)$ had competent level of practices related to endotracheal tube suctioning and follow up chart for I.V line, $(62.5 \%)$ of them had competent level of practices related to gastrostomy feeding while $(82.5 \%, 75 \%)$ of them had incompetent level of practices related to mouth care and care of the chest tube respectively.

Figure (2): Presents total level of the studied nurses' practices regarding care of neonates with TEF. It was found that $32.5 \%$ of the studied nurses had incompetent level of practices while 67.5 of them had competent level of practices.

Table (4): Presents relation between total studied nurses' level of knowledge and practices. It was found that, there is a statistically significance difference was found between their level of knowledge and practices with $\mathrm{X}^{2}(4.02) \mathrm{p}$. value (0.045).

Table (5): Presents correlation between total knowledge and practices score. It was found that, there is statistically significant positive correlation between knowledge score and practices score with $\mathrm{p}=0.005$.

\section{Discussion}

TEF is one of the most serious surgical emergencies in neonates, which require immediate diagnosis and correction. Neonates may be with other serious anomalies, such as congenital heart disease, imperforated anus, intestinal obstruction and anal atresia. The incidence of these associations is around $20 \%$ in esophageal atresia population, but two or more anomalies occur in nearly half of patients. The incidence of TEF nationally was approximately 1 in 3,000 to 4,500 births with a slight preponderance of males in the ratio of female 3:2 (Lockridge, et al., 2002).

Findings of the present study revealed that, more than three quarters of the studied nurses were in the age group ranged from 20 to less than 30 and about one fifth of them were in the age group ranged from 30 to less than 40 years. This finding was in accordance with the result of a study by Mustafa, (2007) who found that the age group of nurses were ranged between $20-<30$ years was $75 \%$ in his study about quality of nurses' practices in neonatal intensive care units. As regard the educational level more than half of them were graduated from secondary school of nursing, one quarter of them graduated from technical institute of nursing and minority of them graduated from health technical institute. This finding go on line with the finding of Ismail \& Abd- Elfattah, (2008) who found that two thirds of nurses had nursing diploma in his study about nurses pitfalls in intensive care unit: effect of intervention educational program.

According to years of experience, it was noticed that less than half of nurses had experience ranged from 5 to less than 10 years while a minority of them had experience of 15 year or more. This finding was in agreement with Kunswa, (2010) who found that the majority of the studied nurses had years of experience ranged from 5-10 years in his study about needs, problems and nursing care of newborn infant.

Regarding nurses' knowledge about TEF, findings of the present study revealed that less than two thirds of the studied nurses define TEF correctly and less than three quarters of them know signs and symptoms of TEF. This finding was disagree with Hassan, (2010) who found that, the majority of 
nurses had poor level of knowledge about signs and symptoms of TEF, according to complications and management of TEF, more than half of them had correct answer. Almost of them had correct answer about pre\& post-operative nursing care of neonates with TEF. This finding was in contrast to Eid, (2005) who concluded that nurses' knowledge regarding to post-operative nursing care was barrier to perform satisfactory immediate postoperative care.

As regard nurses' knowledge about TEF, findings of the current study revealed that more than one third of them had satisfactory level of knowledge while the rest of them had unsatisfactory level of knowledge. This finding was go on line with Hassan, (2010) who found that, half of the nurses had unsatisfactory level of knowledge and was disagreement with Abo-zaid, (2008) who found that, more than two thirds $(67.5 \%)$ of nurses had an average level of knowledge in his study about the quality of nursing care for high risk neonates receiving total parental nutrition.

Regarding the nurses' practices in the present study, it was observed that $(85 \%, 100 \%)$ of the studied nurses had competent level of practices related to naso and oro pharyngeal suctioning and endotracheal tube suctioning respectively. This finding was disagree with Hamed, (1999) who reported that nurses practice regarding suction from nose and mouth of the newborn was performed in unsatisfactory ways.

In the present study the majority of the studied nurses had competent level of practices related to oxygen therapy and nurses strict in following pediatrician orders regarding method of delivery and oxygen saturation. Oxygen therapy is used as needed to maintain normal oxygen saturation. In infants with respiratory failure, endotracheal intubation should be performed (Spitz, et al., 1990). Regarding cannula connection, I.V infusion steps and follow up chart for I.V line it was found that $(97.5 \%, 100 \%)$ of the studied nurses had competent level of practices respectively as NICU nurses had the highest level of practice in cannula connection. Nurses performing the procedure should be well trained as many complications can arise from peripheral intravenous cannulation (Roisin, 2001). As regard gastrostomy care it was noticed that gastrostomy care was performed with satisfactory level $(90 \%)$ when required to the cases. This finding was going on line with Shawky, (2008) who reach to the same end.

As regard total score of the studied nurses' practices regarding neonates with $\mathrm{TEF}$, findings of the current study revealed that less than one third of them had competent level of practices while more than two thirds of them had incompetent level of practices. This finding was go on line with Mohamed, (2014) who found that all the studied nurses had good level of practices in his study of quality of nursing care provided for neonates wit TEF.

There were statistically significant differences were found between total scores of the studied nurses level of knowledge and practices $p=0.045$. This finding was in contrast to Leodoro, (2012) study who found that there was no statistical significance relation between nurses practices and knowledge when evaluated nurses knowledge and practices of pre and post- operative care.

\section{Conclusion}

Based on the results of the present study, it can be concluded that:

Nurses had satisfactory level of knowledge and incompetent level of practices regarding care of neonates with tracheoesophageal fistula.

\section{Recommendations}

Based on the results of the present study the following recommendations can be suggested

- Implementation of periodical educational programs for nurses working at NICU are mandatory, for the purpose of raising and updating the knowledge of nurses regarding TEF.

- Nurses' attendance of films and audiovisual conferences about practical procedures to increase their awareness with the recent approaches related to care of neonates with the high risk conditions.

- Provide nurses with procedure manual hand books containing all necessary information (knowledge) about nursing procedures related to quality of nursing care for neonates with TEF.

- Developing of a nursing protocol related care of neonates with EA/ TEF.

\section{References}

1- Abo - Zaid S., (2008): Quality of Nursing Care for High Risk Neonates Receiving Total Parental Nutrition, Un published, Master Thesis, Faculty of Nursing, Ain Shams, P: 104-108.

2- Eid F., (2005): Ethical issues related to nursing care of pre-operative patient at $\mathrm{El}$ - manial university hospital. Master thesis, Cairo University. Egypt. P: 64.

3- Elizabeth J., Judith A., \& Patricia C., (2006): Manual of Nursing practice, Infectious diseases, $8^{\text {th }}$ ed., Lippincott Williams\& Wilkins, New York, London HonKong, P:1030-1047.

4- Farlex's Medical Dictionary for the Health 
Professions \& Nursing, (2012): available at: www.thefreedictionary. Com

5- Grosfeld J., Ladd A., (2005): Anomalias congênitas. In: Silva ACS e, Pereira RM, Pinheiro PFM., editors.Cirurgia PediátricaCondutas clínicas e cirúrgicas. Rio de Janeiro: Guanabara Koogan, P: 291-298.

6- Hassan A., (2010): Understanding Mechanical Ventilation: A Practical Handbook, $1^{\text {st }}$ ed. , London, Springer Heidelberg Publishers, Chapter 10: The Complication of Mechanical Ventilation, P: 305- 314.

7- Hamed A., (1999): Assessment of nursing care provided to newborns with respiratory distress, thesis, Master degree in pediatric nursing, High institute of nursing, Assuit University.

8- Hockenberry M., Wilson D., \& Marilyn J., (2011): Nursing Care of Infants and Children, $9^{\text {th }}$ ed., Canada, Mosby Company, Chapter 1: Perspective of Pediatric Nursing, P:16.

9- Ismail S., \& Abd -El fattah H., (2008): Basic Neonatology: Protocol s for Neonatal Care Unit s, 2nd ed., Egypt, Chapter 9 : Respiratory Problems, P :205.

10- James S., Ashwill J., \& Nelson K., (2007): Nursing care of children principles and practice, $3^{\text {rd }}$ ed., canda, chapter19, The child with gastrointestinal alteration, P: 519-521.

11- Kunswa A., (2010): Needs, Problems and Nursing Care of Newborn Infants, Pediatric Department, Doctorate Thesis, Faculty of Nursing, Ain Shams University, Egypt, p: 118- 124.

12- Leodoro J., (2012): Nurses 'knowledge and practice of pre- post operative care, Master thesis , Faculty of Nursing, Samar State University, Philippine, P: 70.

13- Lockridge T., Caldwell A., \& Jason P., (2002): Neonatal surgical emergencies: stabilization and management. J Obstet Gynecol Neonatal Nurs, 31(3), P: 39-328.

14- Mohamed R., (2014): Quality of Nursing Care Provided for Neonates with Tracheoesophageal Fistula, Journal of Education and Practice, 5 (3), P: 328 .

15- Mustafa S., (2007): Quality of Nurses Practices in Neonatal Intensive Care Units, Pediatric Department, Master Thesis, Faculty of Nursing, Benha University, Egypt, P: $57-83$.

16- Rebort M., Daniel A., \& Almond P., (2009): Text book, Tracheoesophageal fistula and esophageal Artesia $3^{\text {rd }}$ ed., Philadelphia, Williams and wilkins company,P: 318-323.

17- Rodgers C., Wilson D., Hockenberry M., (2015): Wong's Nursing care of infants and children, 10 ${ }^{\text {th }}$ ed., Canada, Mosby Company, chapter 26: The child with gastrointestinal dysfunction, P: 1110.

18- Roisin Fitzsimon S., (April 2001): Paediatric Accident \& Emergency. University Hospital, Lewisham.; 13 (3).

19- Shawky H., (2008): Assessment of Nursing Care Provided to the newborn with intestinal obstruction at Assuit University Children Hospital. Thesis, Master degree in pediatric nursing, Faculty of Nursing, Assuit University. P: 145-158.

20- Spitz L., Kiely E., Morecroft J., Drake D., (1990): Oesophageal atresia: at-risk groups. J Pediatr Surg, (29), P: 723. 